\title{
ORIGINAL ARTICLE \\ Camellia cake extracts reduce burn injury through suppressing inflammatory responses and enhancing collagen synthesis
}

\author{
Yuxia Liu'†, Xiaomei Xiao ${ }^{2,3 \dagger}$, Luling Ji², Lu Xie ${ }^{4}$, Suzhen Wu** and Zhiping Liu',4* \\ 'Center for Immunology, Key Laboratory of Prevention and Treatment of Cardiovascular and Cerebrovascular \\ Diseases, Ministry of Education, Gannan Medical University, Ganzhou, Jiangxi, China; ${ }^{2}$ Gannan Medical University, \\ Ganzhou, Jiangxi, China; '3epartment of Gynaecology, Huiyang SanHe Hospital, Huizhou, Guangdong, China; \\ ${ }^{4}$ School of Basic Medicine-Gannan Medical University, Ganzhou, Jiangxi, 34 I000, China
}

\section{Popular scientific summary}

- Camellia cake extracts(CCEs) are effective to treat the burn injury in mice.

- CCEs decrease the expression levels of proinflammatory cytokines and increase the collagen synthesis. Furthermore, CCEs reduce the activity levels of oxidative enzymes.

- CCEs reduced the expression levels of pro-inflammatory cytokines in LPS-stimulated human skin keratinocytes possibly through inhibiting NF- $\mathrm{KB}$ signaling pathway.

- Toxicological safety experiments suggest that CCEs are safe for usage.

- CCEs could be an effective, cheap, and safe drug candidate to treat burn injury in human.

\section{Abstract}

Background: Burn injury accidents happen in our daily life, and the burn mortality is especially high in the low-to-middle-income countries. Camellia cake extracts (CCEs) are compound extracts from Camellia cake, and the major ingredients in CCEs may have antimicrobial, anti-oxidative, and anti-inflammatory effects. However, the effects of CCEs on burn inflammation and injury remain unknown.

Objective: This study is to investigate the effects of CCEs in burn injury and explore its mechanism.

Design: First, CCEs were identified to mainly contain camelliaside A and B using Ultra High Performance Liquid Chromatography-Time of Flight Mass Spectrometer (UHPLC-TOF-MS) method. Second, the CCEs' effect on burn was tested. Burn was induced by boiling water in mice, and then CCEs $(30,50$, and $100 \mathrm{mg} / \mathrm{mL})$ were applied on the damaged skin at 3, 7, and 14 days after burn induction.

Results: The results showed that CCEs protected the skin from burn-induced inflammation and enhanced the wound healing in a dose-dependent manner. CCEs decreased the expression levels of various cytokines including $I L-6, T N F-\alpha, I L-1 \beta, M C P-1, T G F-\beta$, and $I L-10$, as well as inflammatory related factors iNOS. Moreover, CCEs increased the levels of collagens, including the mRNA of COL $\alpha-1$ and $C O L-3$, and inhibited the mRNA of $M M P-1$ and TIMP-1, and increased the collagen staining. CCEs also reversed the impairment of activity levels of anti-oxidative enzymes. Furthermore, CCEs suppressed the gene expression of pro-inflammatory cytokines in LPS-stimulated human skin keratinocyte, possibly through inhibiting NF- $\mathrm{B}$ signaling pathway. In addition, toxicological safety experiments on CCEs showed that the oral median lethal dose (LD50) was 2,000 mg/kg, the percutaneous LD50 was greater than 2,000 mg/kg, and CCEs did not cause gene mutation.

Conclusion: CCEs exert a potent anti-inflammatory effect against burn damage in mice. And toxicological safety experiments suggest that CCEs are safe for usage.

Keywords: Camellia cake extracts; burn injury; inflammatory response; collagen

To access the supplementary material, please visit the article landing page

Received: 25 November 20 I9; Revised: 24 January 2020; Accepted: 27 January 2020; Published: 6 March 2020

†These authors are the co-first authors. 
$\mathrm{B}$ urns are usually defined as skin wounds caused by thermal/heat exposure, electricity, chemical materials, radiation exposure, or others (1). In accordance with the latest report in 2018 from the World Health Organization, about 180,000 deaths occur due to thermal burn wounds each year (2). The burn mortality is especially high in the low-to-middle-income countries (3).

The skin consists of three different layers, including epidermis, dermis, and hypodermis. Burn wound healing processes include inflammation, proliferation, reepithelization, and remodeling phases (4). Burn wound is classified into four degrees. The third-degree burn (full-thickness burn) induces damage in both the epidermis and the underlying layer of the skin (5). Currently, $1 \%$ silver sulfadiazine (SSD) and some proprietary Traditional Chinese Medicines, such as Meibao burn fire plaster (Mebo), are commonly used, particularly in China, to treat bury injury. These drugs reduce the bacterial infection in wound areas. However, SSD has some disadvantages, such as the formation of a pseudoeschar layer on the burn wound, a cytotoxic effect on keratinocyte as well as fibroblast, and the need for frequent dressing changes (6). As an adjuvant drug to scald therapy, Mebo has a good effect in the treatment of burn injury. However, its high price prevents patients in the developing countries to use it (7). Better alternative burn drugs with few adverse effects and low price are needed.

Camellia oleifera Abel is a plant cultivated in the southern part of China. Its seeds are used for oil production. Camellia oil has been shown to reduce gastrointestinal mucosal damage or colitis (8-10). The by-products of oil production are known as Camellia oil cakes. They have traditionally been used as waste residues such as animal feed or been incinerated for heating. Therefore, its biological values have yet to be fully utilized. Camellia oil cake or its components may have anti-inflammatory or anti-oxidative functions by regulating mediators for both inflammation initiation and inflammation resolution (11). Camellia cake extracts (CCEs) are compound extracts from Camellia cake, and the major ingredients such as sasanquasaponin (SQS) and flavonoid may have antimicrobial, anti-oxidative, and anti-inflammatory effects. A study showed that SQS increased the viability of RAW264.7 cells infected with Staphylococcus aureus, Escherichia coli, Bacillus subtilis, or some fungi, indicating its anti-microbial effects (12). Another study examined the effect of CCEs on the foot swelling induced by carrageenan-induced paw edema in rats and croton oil-induced ear inflammation in mice by inhibiting the production of IL-1 $\beta$, TNF- $\alpha$, and PGE $_{2}$ (13). Camelliaside $\mathrm{A}$ and $\mathrm{B}$ are two Camellia flavonol triglycosides, and their enzymatic products were shown to inhibit cellular nitrite oxide, prostaglandin E, and IL-6 production by lipopolysaccharide-stimulated RAW 264.7 cells $(14,15)$. However, whether CCEs can treat burn-induced inflammation remains unknown.

In this study, we investigated the effects of CCEs on burn and identified that CCEs could reduce burn inflammation and enhance wound healing, possibly through suppressing the expression of pro-inflammatory cytokines and anti-oxidative enzymes, and promoting the expression of collagen-associated genes. This will facilitate the identification of the novel anti-inflammatory and anti-oxidative drug candidates with fewer side effects and lower prices.

\section{Materials and methods}

\section{Experimental animals}

Six- to eight-week-old C57BL/6 mice were obtained from Model Animal Research Center of Nanjing University (Nanjing, Jiangsu, China). The study was approved by the Institutional Research Ethics Committees of Gannan Medical University.

\section{Camellia cake extracts and structural analysis}

The CCEs were provided by Hongliang Li from the College of Pharmacy, Gannan Medical University. The dry powder of CCEs was dissolved in 30\% methanol and diluted to an appropriate concentration. The analysis of extracted mixture of CCEs was performed using an Agilent 1290 UHPLC tandem 6230 ESI-TOF MS system (Agilent Technologies, Santa Clara, CA, USA) controlled by MassHunter Workstation software. An Agilent Eclipse plus $\mathrm{C}_{18}$ column $(100 \times 2.1 \mathrm{~mm}, 1.8 \mu \mathrm{m})$ was used to separate the extracts, with the column temperature set at $35^{\circ} \mathrm{C}$, and the flow rate was $0.3 \mathrm{~mL} / \mathrm{min}$. The injected volume was $2 \mu \mathrm{L}$. The mobile phase consisted of $0.1 \%$ formic acid aqueous solution (A) and $0.1 \%$ formic acid methanol (B) using a gradient elution of $5-40 \%$ $\mathrm{B}$ at $0-5 \mathrm{~min}, 40-75 \% \mathrm{~B}$ at $5-11 \mathrm{~min}, 75 \% \mathrm{~B}$ isocratic from 11 to $13 \mathrm{~min}, 75-100 \% \mathrm{~B}$ at $13-18 \mathrm{~min}$, and $100 \%$ B at 18-21 min. The MS acquisition parameters were as follows: gas temperature, $550^{\circ} \mathrm{C}$; gas flow rate, $12 \mathrm{~L} / \mathrm{min}$; nebulizer, $35 \mathrm{psig}$; shell gas temperature, $350^{\circ} \mathrm{C}$; shell gas flow rate, $10 \mathrm{~L} / \mathrm{min}$; capillary voltage, $3,500 \mathrm{~V}$; fragmentor, $380 \mathrm{~V}$; and skimmer, $65 \mathrm{~V}$.

\section{Burn injury}

Mice were anesthetized by an intraperitoneal injection of $5 \%$ chloral hydrate $(0.01 \mathrm{~mL} / 10 \mathrm{~g})$. The dorsal hairs were clipped, and then, mice were put on the panel control; mouse limbs were stretched with rubber band to expose $30 \%$ total body surface area in prone position. Subsequently, a round plastic tube with a diameter of $1.5 \mathrm{~cm}$ was placed upright on the mouse back, and one end contact with the skin, and $2 \mathrm{~mL} 100^{\circ} \mathrm{C}$ water was poured through the other end. The burn injury area is about $\pi^{*}(1.5 / 2)^{2}=1.76 \mathrm{~cm}^{2}$. After that, 
a third degree burn wound was established on the shaven area by immersing in $100^{\circ} \mathrm{C}$ water for $25 \mathrm{~s}$. The burn injury area is about $\pi^{*}(1.5 / 2)^{2}=1.76 \mathrm{~cm}^{2}$. After that, a thirddegree burn wound was established on the shaven area by immersing in $100^{\circ} \mathrm{C}$ water for $25 \mathrm{sec}$. The burn area was scrub debrised with dry sterile gauze and rinsed with $0.9 \%$ sterile saline. Mice were resuscitated with $4 \mathrm{~mL} /$ percentage of total body surface area burn/kg Ringer's lactate by intraperitoneal injection. Sham animals were subjected to identical procedure and resuscitation, but immersed in room temperature water. We dipped $0.5 \mathrm{~mL}$ of drugs into a cotton swab and smeared in the area of scald twice a day (9 AM and 5 PM every day). Different cotton swabs were used for each mouse.

Animals were randomly assigned to five groups: Sham: no burn injury or medicine was given. Burn: burnt but no medicine was given. Burn + vehicle: burnt and then smeared with $0.05 \mathrm{~mL}$ of water. Burn + Mebo: burnt and then smeared with $0.05 \mathrm{~mL}$ of Mebo burn fire plaster (Mebo International, China). Burn + CCEs-L: burnt and then treated with $0.05 \mathrm{~mL}$ of $30 \mathrm{mg} / \mathrm{mL}$ CCEs solution daily. Burn + CCEs-M: burnt and then treated with $0.05 \mathrm{~mL}$ of $50 \mathrm{mg} /$ mL CCEs solution daily. Burn + CCEs-H: burnt and then treated with $0.05 \mathrm{~mL}$ of $100 \mathrm{mg} / \mathrm{mL}$ CCEs solution daily.

The wound areas were measured by tracing the boundary of the scars on days $1,3,7$, and 14 . The healing rates were calculated based on the diameter of the wound area and the following equation: wound healing rate $(\%)=$ [(wound area on day 0 - wound area on day $N$ )/wound area on day 0$] \times 100 \%$. In addition, on days $1,3,7$, and 14 after burn injury, mice were sacrificed and the wounded skin was removed for further analysis.

\section{qRT-PCR}

The skin tissues mainly from burn wound area and 2-mm width of skin tissues from the surrounding area or cells were collected. Total RNA was prepared using the TRIzol method (Life Technologies, Rockville, MD) following the manufacturer's instructions. RNA was reversely transcribed into cDNA, and qPCR was performed by CFX96 Real-Time PCR system (Applied Bio systems) using SYBR ${ }^{\circledR}$ Select Master Mix (Applied Bio systems). beta-actin ( $\beta$-actin) was selected as the internal reference. The messenger RNA (mRNA) levels of $I L-6, T N F-\alpha$, $I L-1 \beta, M C P-1, i N O S, T G F-\beta, I L-10, C O L \alpha-1, C O L-3$, $M M P-1$, and TIMP-1 were determined by qRT-PCR. The primer sequences were shown in Supplementary Table 1.

\section{Histopathological analysis}

At 1, 3, 7, and 14 days after burn injury, a circular skin wound specimen was evenly divided into four parts, and each part contains a full layer of skin tissues. One part of skin tissues was stained for histological analysis, and the other part was used for PCR or other biochemical analysis.
Skin tissues for histological analysis were washed, fixed in $10 \%$ buffered formaldehyde, and embedded in paraffin. Tissue sections were stained with hematoxylin and eosin (H\&E) stain (Solarbio, USA). The sections were examined under a light microscopy (DM 6000B, Leica Inc. Wetzlar, Germany) with a microscope digital image output system (idea SPOT, Diagnostic Instruments Inc., Sterling Heights, MI, USA).

Histological scoring system was modified based on previous literatures (16-18). The analysis was performed by a pathologist in a blinded fashion as a combination of inflammatory cell infiltration (score $0-5$ ), necrosis area percentage (score $0-5$ ), and granulation tissue percentage (score $0-5$ ). The number of inflammatory cells between 80 and 100 in each high magnification was scored as 0 , $60-80$ was scored as $1,40-60$ was scored as $2,20-40$ was scored as 3,1-20 was scored as 4, and no inflammatory cell infiltration was scored as 5 . For necrosis area, the necrosis area percentage between 80 and $100 \%$ in each high magnification was scored as $0,60-80 \%$ was scored as 1 , $40-60 \%$ was scored as $2,20-40 \%$ was scored as 3, $1-20 \%$ was scored as 4 , and no necrosis area was scored as 5 . The granulation tissue percentage between 80 and $100 \%$ was scored as $5,60-80 \%$ was scored as $4,40-60 \%$ was scored as $3,20-40 \%$ was scored as $2,1-20 \%$ was scored as 1 , and no granulation tissue was scored as 5 .

For collagen staining, sections from paraffin-embedded tissues were stained with collagen using a commercial Chlorazol fast pink staining kit following the manufacture's instruction (Solarbio, Beijing, China).

\section{ELISA analysis}

Skin tissues were homogenized in Radio-Immunoprecipitation Assay (RIPA) buffer supplemented with protease and phosphatase inhibitors (Roche) and centrifuged at $15000 \mathrm{rpm}$ for 30 minutes, protein supernatant were collected. The protein level of inflammatory factors IL-6 and TNF-a were measured using commercially available ELISA kits according to the manufactures' instructions (Elabscience, Wuhan, China).

\section{Measurement of anti-oxidative enzymes}

The activities of catalase (CAT) and superoxide dismutase (SOD) were assayed according to previously described methods (9). CAT and SOD activities in the skin homogenate were assayed using commercial kits (Nanjing Jiancheng Bioengineering Institute, Nanjing, Jiangsu, China) following the manufacturers' instructions.

\section{Culture of human skin epithelial cells}

Immortalized human skin keratinocyte cell line Hacat (ATCC\#1295) was purchased from Cells Center of Shanghai Institutes for Biological Sciences (Chinese Academy of Science, Shanghai, China). Cells were cultured 
in DMEM containing heat-inactivated FBS $(10 \%, v / v)$, penicillin $(100 \mathrm{IU} / \mathrm{mL})$, and streptomycin $(100 \mu \mathrm{g} / \mathrm{mL})$ and were grown at $37^{\circ} \mathrm{C}$ in a humidified incubator in a $5 \% \mathrm{CO}_{2}$ atmosphere. Confluent cells were transferred into 6-well plates overnight. For CCEs+liposaccharide (LPS) group, $1 \mathrm{ug} / \mathrm{ml}$ CCEs were added into wells for 12 hours, then $1 \mathrm{ug} / \mathrm{ml}$ LPS were then added into wells for 2 hours. For LPS+CCEs group, $1 \mathrm{ug} / \mathrm{ml}$ LPS were then added into wells for 2 hours and then $1 \mathrm{ug} / \mathrm{ml} \mathrm{CCEs} \mathrm{were} \mathrm{added} \mathrm{into}$ wells. Cells not treated or treated with LPS only were used as Control or LPS groups. After that, cells were collected in TRIzol, and then RNA was isolated. RNA was then reverse-transcribed into cDNA, and the gene expression of IL- 6 and TNF- $\alpha$ was analyzed using quantitative real-time PCR. In addition, cells were collected and protein were extracted in RIPA buffer supplemented with protease and phosphatase inhibitors (Roche) for Western-blot analysis.

\section{Western blot analysis}

Protein extracts were resolved in $12 \%$ Sodium Dodecyl Sulfate-Polyacrylamide Gel Electrophoresis (SDS-PAGE) and transferred onto Poly vinylidene fluoride (PVDF) membranes. Membranes were blocked in $5 \%$ milk for $1 \mathrm{~h}$ and incubated in primary antibodies, p-IкB (9241, Cell Signaling) and I-kB (9242, Cell Signaling), overnight at $4^{\circ}$. Membranes were incubated with Horseradish Peroxidase (HRP)-conjugated secondary antibody for 1 $\mathrm{h}$, and proteins were visualized using Electro-Chemi-Luminescence (ECL) substrate.

\section{CCEs safety analysis}

To test the safety of CCEs with classical toxicology experiments, the cute dermal toxicity is determined by the limit test method; 10 Sprague Dawley (SD) rats (5 female and 5 male) were selected and CCEs were applied to the marked area of the animal back for $24 \pm 1 \mathrm{~h}$. After that, CCEs were removed with purified water, and the day of administration was designated as D1. The animals were observed for 14 days after administration, and cage observation was performed once a day. The rats were weighed at D1 (before administration), D8, and D15. Animals that were still alive at the end of the observation period (D15) were grossly dissected.

Acute oral toxicity was measured by up-and-down procedure (UDP) with doses of 175,550 , and $2,000 \mathrm{mg} / \mathrm{kg}$ (upper dose). The starting dose was $550 \mathrm{mg} / \mathrm{kg}$. One animal at a time, and each animal was administered at a time interval of $48 \mathrm{~h}$. The dose administered to the second animal depends on the result of the first animal. If the animal survives $48 \mathrm{~h}$ after administration, the dose will increase; if the animal dies within $48 \mathrm{~h}$, the dose will be adjusted to the lower level. The observation period of each animal is no more than 14 days. They were weighed on D1 (before administration), D8, and D15. A detailed clinical observation was performed once a day, and the animals that were still alive at the end of the trial (D15) were grossly dissected.

The Ames test was used to assess whether CCEs induced genetic mutations. Five CCE doses of 50, 5, 0.5, 0.05, and $0.005 \mathrm{mg} / \mathrm{mL}$ were used. The final doses were 5,1 , and 0.2 , $0.04,0.008 \mathrm{mg} / \mathrm{dish}$, respectively. Another negative control group (purified water) and a positive control group ( $\pm \mathrm{S} 9$ mixture, 2-aminopurine, cyclophosphamide; -S9 mixture, ICR191, 2-nitroguanidine, sodium azide, mitomycin C) were used. Detection of the number of revertant colonies of histidine-deficient Salmonella typhimurium (TA97, TA98, TA100, TA102, TA1535) (Shanghai Beinuo Biotechnology, Shanghai, China) in $\pm S 9$ (with or without hepatic microsomal enzyme metabolic activation system) was performed.

\section{Statistical analysis}

Data were analyzed using GraphPad prism 7.0 software. Data were expressed as the mean \pm SEM. Data comparisons between two groups were analyzed using $t$ test, and those among different treatment groups were done using one-way analysis of variance (ANOVA). $P<0.05$ was considered statistically significant.

\section{Results}

\section{The structural analysis of CCEs}

Most of the compounds yield stronger signal under positive ion mode rather than negative in ESI/MS. According to the accurate mass and fragment information, camelliaside A, camelliaside B, 1-phenylethanol O- $\beta$-D-glucopyranoside, and $\mathrm{N}-\beta$-alanyldopamine $\mathrm{O}-\beta$-D-glucopyranoside were identified as the major constituents using UHPLC-TOF/ MS approach. Taken camelliaside A as an example, the peak eluted at 5.455 min yielded a high abundance signal at $\mathrm{m} / \mathrm{z} 779.2032$ and 757.2204, which corresponded with $[\mathrm{M}+\mathrm{Na}]^{+}$and $[\mathrm{M}+\mathrm{H}]^{+}$ions of $\mathrm{C}_{33} \mathrm{H}_{40} \mathrm{O}_{20}$, respectively. By searching against 'Dictionary of Natural Products', the accurate mass information were attributed to kaempferol 3-glycosides (synonym camelliaside A). And the fragment at $\mathrm{m} / \mathrm{z} 287.0556$ is the signal of flavonoid nucleus. The information of two representative compounds was shown in Fig. 1.

\section{The establishment of a full-thickness scald burn model}

To establish a third-degree dermal injury model, we evaluated burn depth at $25 \mathrm{~s}$ exposures to boiling water. Mice were separated into sham or burn groups at day 0 , and burn group mice were subjected to a $100^{\circ} \mathrm{C}$ boiling water for 25 seconds to cause a scald burn (n (sham) $=8$, $\mathrm{n}$ (burn) $=7$ in each group). Sham animals were placed in room temperature water (Fig. 2a, c). Skin was harvested at $24 \mathrm{~h}$ and evaluated by traditional H\&E staining for evidence of cell necrosis, and destruction included skin appendages and the dermal/subcutis junction. Additionally, the $25 \mathrm{~s}$ burn animals significantly demonstrated injury 
a

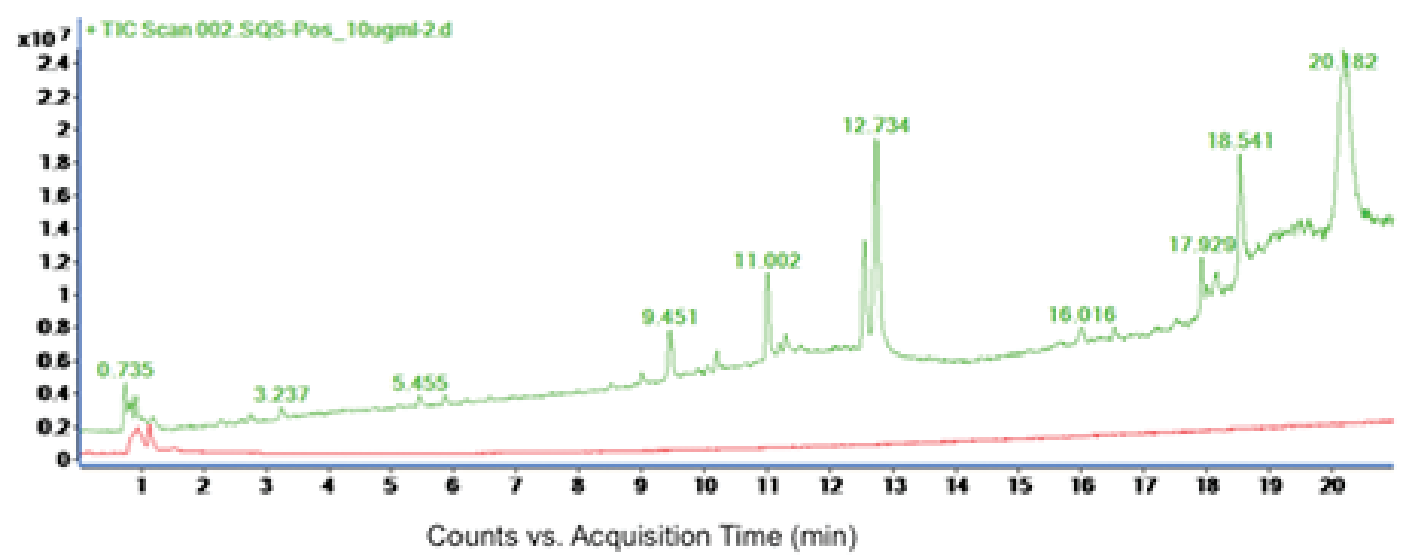

b

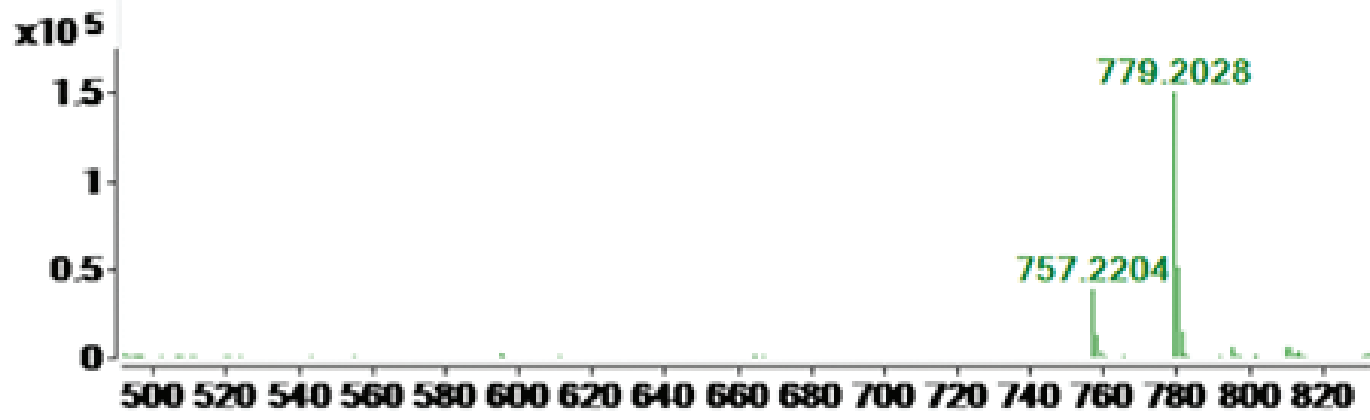

C

Counts vs, Mass-to-Charge $(\mathrm{m} / \mathrm{z})$

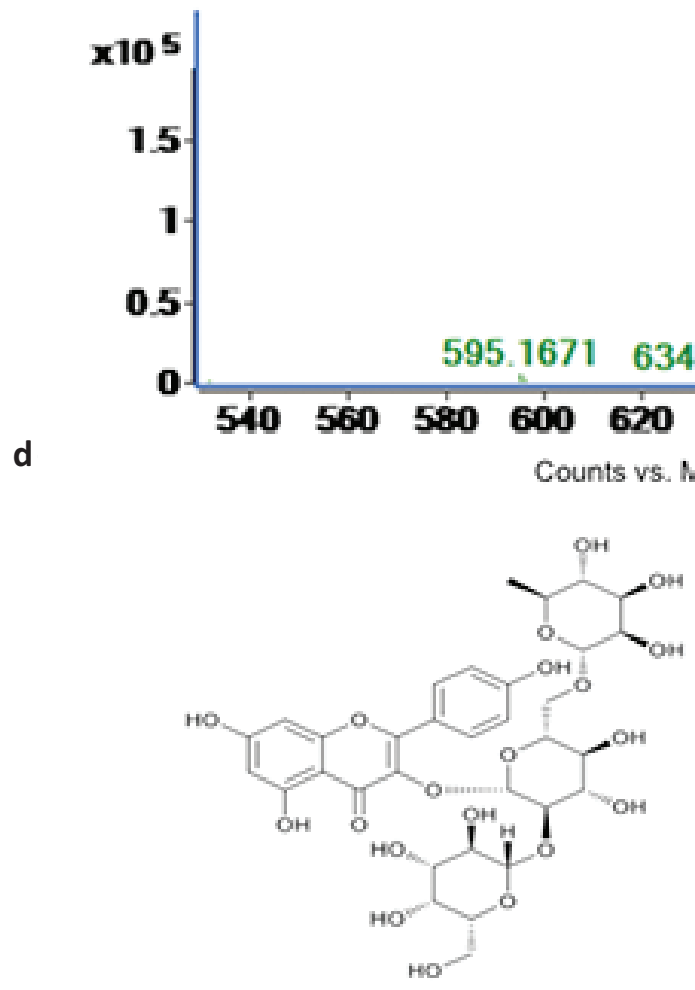

Camelliaside A<smiles>C[C@H]1OC(=O)[C@H](O)[C@@H](O)[C@H]1O</smiles>

Camelliaside B

Fig. 1. The identification of Camellia cake extracts (CCEs) by LC/ESI-TOF-MS under positive ion mode. (a) Total ion chromatogram (TIC) of CCEs; (b) Mass spectrum of representative compound 1 - Camelliaside A; (c) Mass spectrum of representative compound 2 - Camelliaside B; (d) Chemical structures of camelliaside A and camelliaside B. 
a

Evaluated whether the scald model is successful

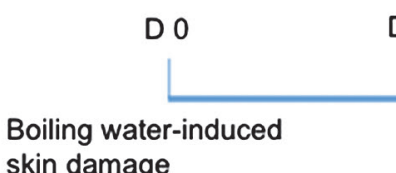

Collected tissue
Treated with water or Mebo or CCEs $(30,50,100 \mathrm{mg} / \mathrm{ml})$,twice per day

$\begin{array}{lll}\text { D } 3 & \text { D } 7 & \text { D } 14\end{array}$

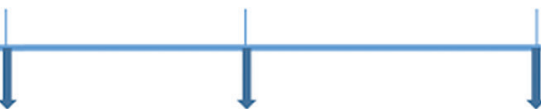

Collected tissue Collected tissue

Collected tissue

b

Burn+Vehicle

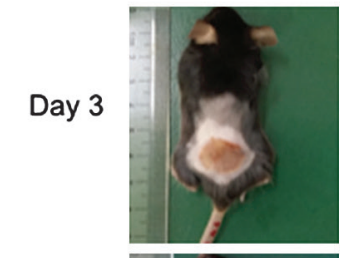

Day 3

Day 7

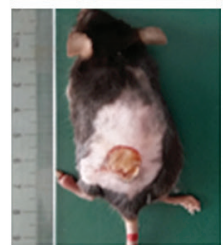

Day 14

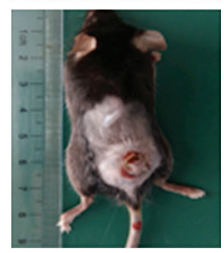

Burn+Mebo
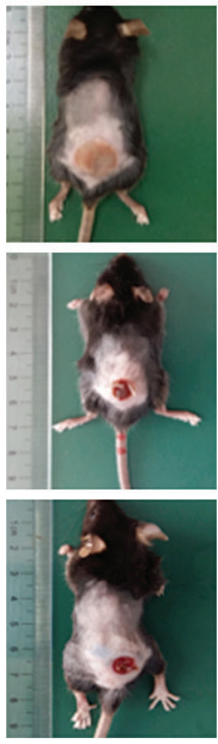

Burn+CCEs-L
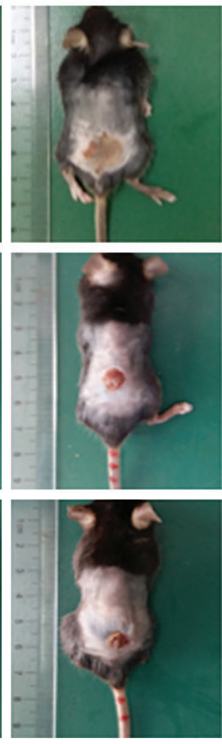

Burn+CCEs-M
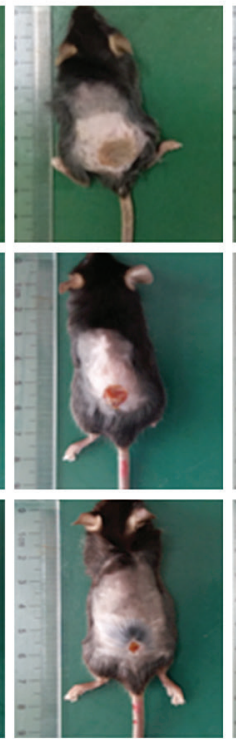

Burn+CCEs-H
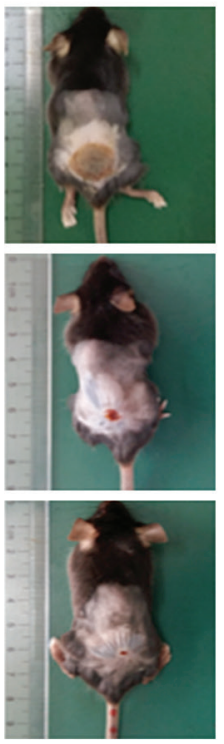

C

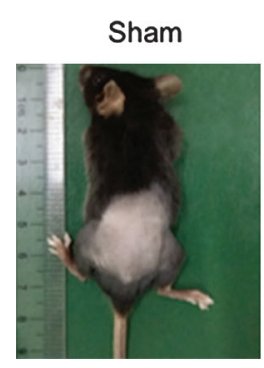

Burn

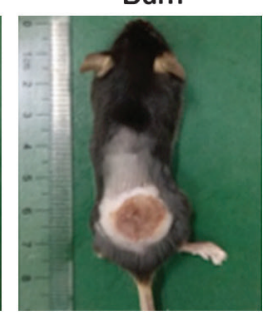

d

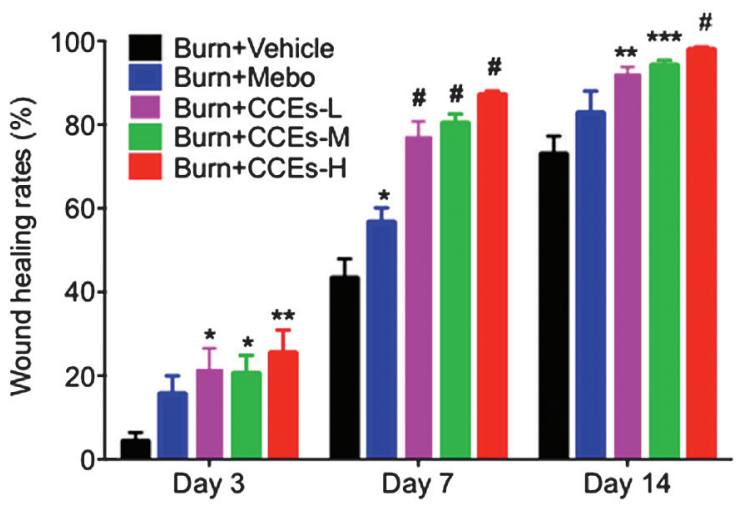

Fig. 2. The effect of Camellia cake extracts (CCEs) on the burn injury of C57BL/6 mice. (a) The $100^{\circ} \mathrm{C}$ boiling water was used to cause a third-degree burn injury on the mice in $25 \mathrm{sec}$ (b) Representative picture of wound healing from 1, 3, 7, and 14 days after boiling water treatment. The mice were administrated with water, Mebo, or CCEs (30, 50, and 100 mg/mL) for 3, 7, and 14 days, respectively. (c) The control group was sham-treated and the burn group had skin scald only at day 0 . (d) Wound areas were evaluated at days 3, 7, and 14, and wound-healing rates were calculated. Data were expressed as mean \pm SEM for $n(\operatorname{Sham})=8$, $n($ Burn $)=7$ in day $1, n($ Vehicle $)=9, n($ Mebo $)=8, n($ CCEs-L $)=8, n($ CCEs-M $)=9, n($ CCEs-H $)=9$ in day 3, $n($ Vehicle $)=10$, $n(\mathrm{Mebo})=10, n(\mathrm{CCEs}-\mathrm{L})=11, n(\mathrm{CCEs}-\mathrm{M})=11, n(\mathrm{CCEs}-\mathrm{H})=11$ in day $7, n($ Vehicle $)=8, n(\mathrm{Mebo})=10, n(\mathrm{CCEs}-\mathrm{L})=9$, $n($ CCEs-M $)=9, n($ CCEs-H $)=9$ in day $14,(* P<0.05, * * P<0.01, * * * P<0.001, \# P<0.0001$ vs. Burn+Vehicle group $)$ CCEs-L (CCEs, $30 \mathrm{mg} / \mathrm{mL})$; CCEs-M (CCEs, $50 \mathrm{mg} / \mathrm{mL})$; CCEs-H (CCEs, $100 \mathrm{mg} / \mathrm{mL})$. 
involving the lesions in epidermal dermal, deep subcutaneous tissue, vessels, glands, and subcutaneous muscle (Fig. 3a). Therefore, a third-degree scalded skin model in mouse back was established.

\section{The effect of CCEs on wound healing in burn injury}

Skin wound healing was observed on 3, 7, and 14 days after burn injury. The appearance of the burn injury mice treated with three different concentrations of CCEs showed a closed wound in the day 7 or 14, especially for treatment with CCEs-H in the day 14. Interestingly, animals treated with CCEs are more effective than Mebo in promoting wound healing (Fig. 2b). During days 3, 7, and 14 , mice receiving various concentrations $(30,50$, and 100 $\mathrm{mg} / \mathrm{mL})$ of CCEs showed a significant $(P<0.05)$ effect on promoting wound healing in comparison with Burn + vehicle group. Moreover, $100 \mathrm{mg} / \mathrm{mL}$ concentration of CCEs exhibited the greatest effect on wound healing after 14 day of treatment $(P<0.05)$. Different dose $(30,50$, and 100 $\mathrm{mg} / \mathrm{mL}$ ) of CCEs for 3, 7, and 14 days resulted in the significant $(P<0.05)$ increase in wound healing rates, respectively, compared to the Burn + vehicle group (Fig. 2d). In addition, burn + Mebo also showed a significant improvement in wound healing at day 7. Furthermore, various concentrations of CCEs induced a significant dose-dependent $(P<0.05)$ effect in enhancing wound healing. These results indicate that CCEs might have the potential to help mice get recovery from scalded skin damage.

\section{The effect of CCEs on pathological lesions on burn injury}

The protective effects of CCEs against burn injury were also examined by $H \& E$ staining. In the third-degree scalded skin of mouse back, damage as well as necrosis and lymphocyte infiltration in epidermal dermal lesion, deep subcutaneous tissue, and subcutaneous muscle were observed. However, mice treated with CCEs at 30, 50, and $100 \mathrm{mg} / \mathrm{mL}$ for 3,7 , and 14 days showed improved wound healing in a dose-dependent manner. In 7 and 14 days, $100 \mathrm{mg} / \mathrm{mL}$ CCEs treatment not only remarkably reduced inflammatory cell infiltration and the number of necrosis tissue but also increased the presence of granulation tissue (Fig. 3b, c).

\section{The effect of CCEs on boiling water-induced changes on gene and protein expression of pro- or anti-inflammatory cytokines in burn mice}

Downregulation of inflammatory cytokines plays an important role on wound healing (19). In this study, the effects of CCEs on pro-inflammatory cytokines Interleukin 6 (IL-6), Tumor Necrosis Factor alpha (TNF- $\alpha$ ), Interleukin 1 beta (IL-1 $\beta$ ), Monocyte Chemoattractant Protein-1 (MCP-1), transforming growth factor- $\beta$ (TGF- $\beta$ ), and inflammatory cytokine Inducible Nitric Oxide Synthase (iNOS) were evaluated. Burn group mice showed a significant $(P<0.05)$ increase in the mRNA level of $I L-6, T N F-\alpha, I L-1 \beta, M C P-1$, and $i N O S$. The mRNA levels of $I L-6, T N F-\alpha, I L-1 \beta, M C P-1$, and $i N O S$ in mice treated with Mebo or CCEs (30, 50 and $100 \mathrm{mg} / \mathrm{mL} /$ day) were remarkably reduced in 3,7 , and 14 days in a dose-dependent manner, and the $100 \mathrm{mg} / \mathrm{mL}$ concentration exhibited the greatest effect on reducing inflammatory factors production, in comparison with the Burn + vehicle group (Figs. $4 \mathrm{a}, \mathrm{b}$ and $5 \mathrm{a}-\mathrm{c}$ ). In order to confirm the gene expression changes, we tested the protein levels of IL-6 and TNF- $\alpha$ at day 3, 7 and 14 after burn treatment and found that Meibo and CCEs treatment induced similar marked reduction in the production of IL-6 and TNF- $\alpha$ in skin tissues (Fig. 4c, d). We also tested the effect of CCEs on the gene expression of anti-inflammatory cytokines including TGF- $\beta$ and $I L-10$. Surprisingly, CCEs also decreased the mRNA levels in both TGF- $\beta$ and $I L-10$ (Fig. 5 d, e) in a dose-dependent manner. These results suggest that CCEs have an anti-inflammatory effect by inhibiting the expression of inflammatory cytokines in burn damage.

\section{The effect of CCEs on COL $\alpha-I$, COL-3, MMP-, I and TIMP-I $m R N A$ expression in burn mice}

We then evaluated the effect of CCEs in promoting wound healing by investigating the mRNA levels of genes associated with wound healing in scalded skin tissues. On the one hand, treatment of CCEs at $100 \mathrm{mg} / \mathrm{mL}$ for 3, 7, and 14 days (Fig. 6a, b) showed a notable increase in the mRNA levels of collagens such as COL $\alpha-1$ and $C O L-3$ relative to the Burn + vehicle group $(P<0.05)$. However, there were no significant changes in $C O L \alpha-1$ production at day 7. On the other hand, treatment of Mebo or CCEs at 30,50 , and $100 \mathrm{mg} / \mathrm{mL}$ for 3,7 , and 14 days showed a marked decrease in the gene expression levels of $M M P-1$ and TIMP- 1 in comparison with the Burn + vehicle group $(P<0.05)$ (Fig. 6c, d). Consistently, CCE treatment increased the collagen protein expression, demonstrated by higher levels of collagen staining in skin following CCEs treatment (Fig. 6e). Accordingly, these results suggest that CCEs increased the gene expression of the collagens and decreased the levels of metalloproteinase, which play key roles in the regulating wound healing.

The effect of CCEs on activity levels of anti-oxidative enzymes Burn injury caused significant reduction in the activity levels of the anti-oxidative enzymes including SOD and CAT at day 7 and day 14 after treatments. However, administration of Mebo and various concentrations of CCEs, especially high dose of CCEs, exhibited marked reversal of the impairment of antioxidant enzyme system in the skin tissues compared with the burn groups (Fig. 7a-d). These results indicate that CCEs treatment could reverse the activity levels of anti-oxidative 
a

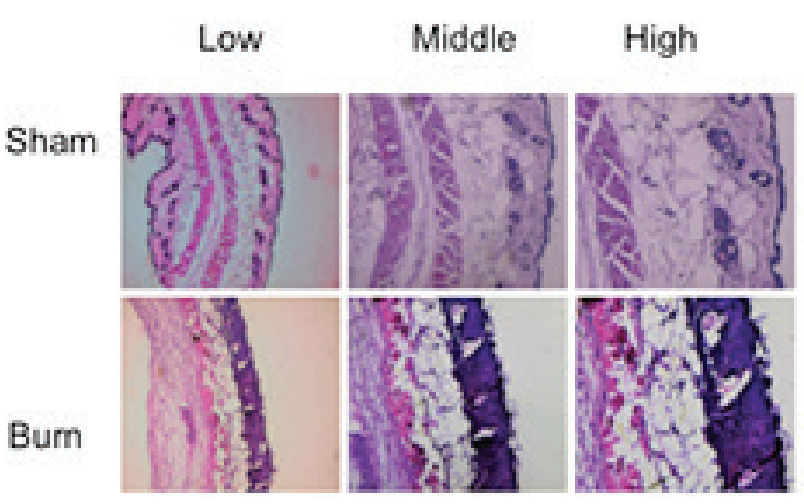

C

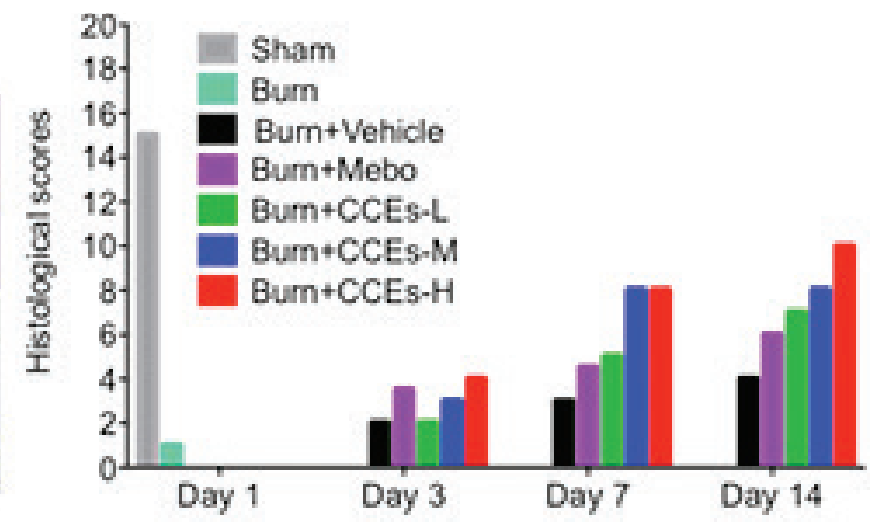

b

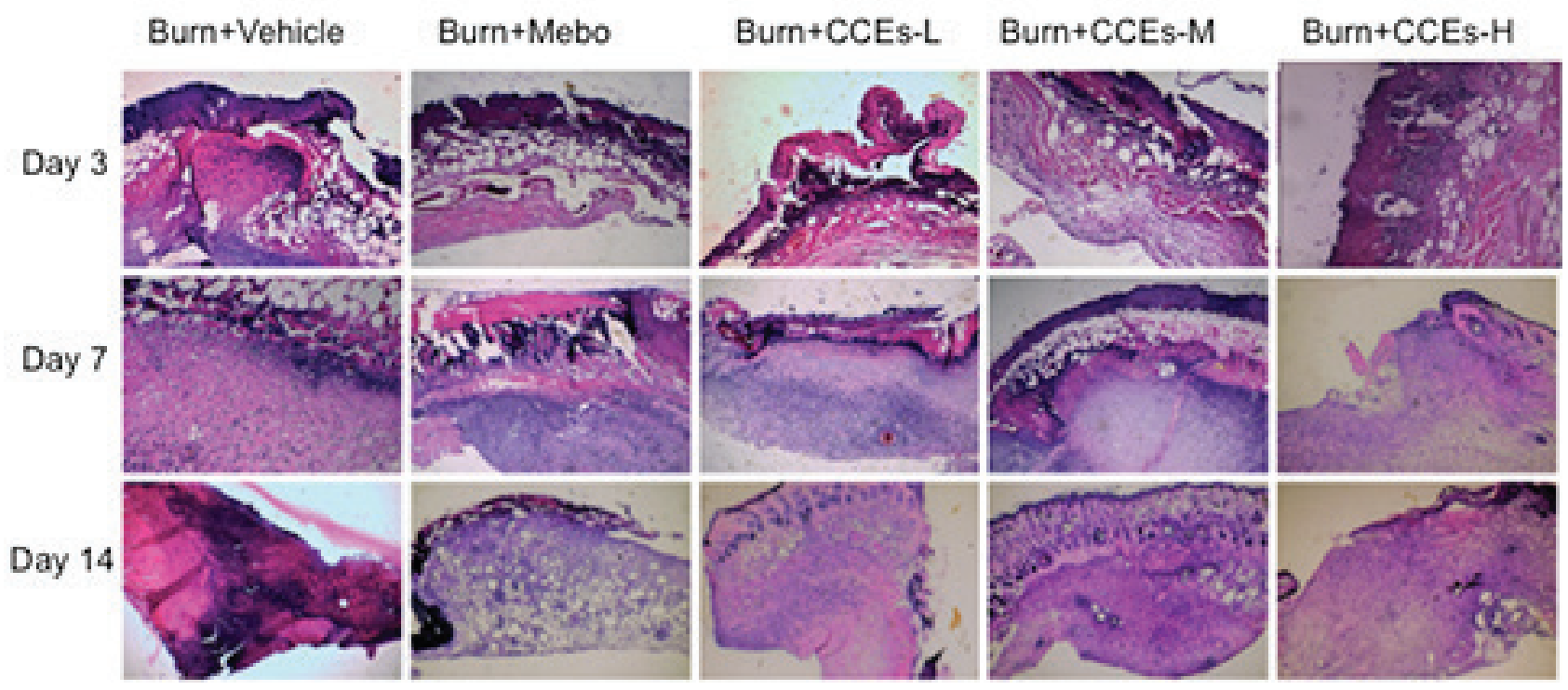

Fig. 3. Histopathological changes in the scalded skin after Camellia cake extracts (CCEs) treatment. (a) Histological injury scores of the skin after topical administration of water, Mebo, or different doses of CCEs in skin scald mice. Score parameters include inflammatory cell number, tissue necrosis, and granulation tissue. The boiling water-induced skin scalds in mice was treated with or without CCEs for different time points and skin tissues were collected for histological analysis. (b) H\&E staining of skin tissues $40 \times$ magnifications.

enzymes, which is consistent with the anti-inflammatory functions.

The anti-inflammatory effect of CCEs on the LPS-stimulated skin keratinocyte cells

In order to further investigate the anti-inflammatory effect of CCEs, we treated the human skin keratinocyte cells with CCEs, then stimulated the cells with LPS(CCEs+LPS), a potent stimulus to activate innate immune signaling such as Toll-like receptor 4 , or stimulated cells withe LPS and then treated with CCEs (LPS+CCEs).
Cells not treated or treated with LPS only were used as Control or LPS groups. After that, cells were collected for gene expression analysis of pro-inflammatory cytokines including IL-6 and TNF- $\alpha$ using quantitative real-time PCR. Consistently with in vivo results, CCEs treatment significantly suppressed the gene expression of IL-6 and TNF- $\alpha$, which was robustly elevated by LPS stimulation (Fig. 8a, b). In addition, cells were collected for protein analysis of activation of $\mathrm{NF}-\kappa \mathrm{B}$ signaling pathway, a major pathway to regulate the production of pro-inflammatory cytokines. Consistently, CCEs treatment before 


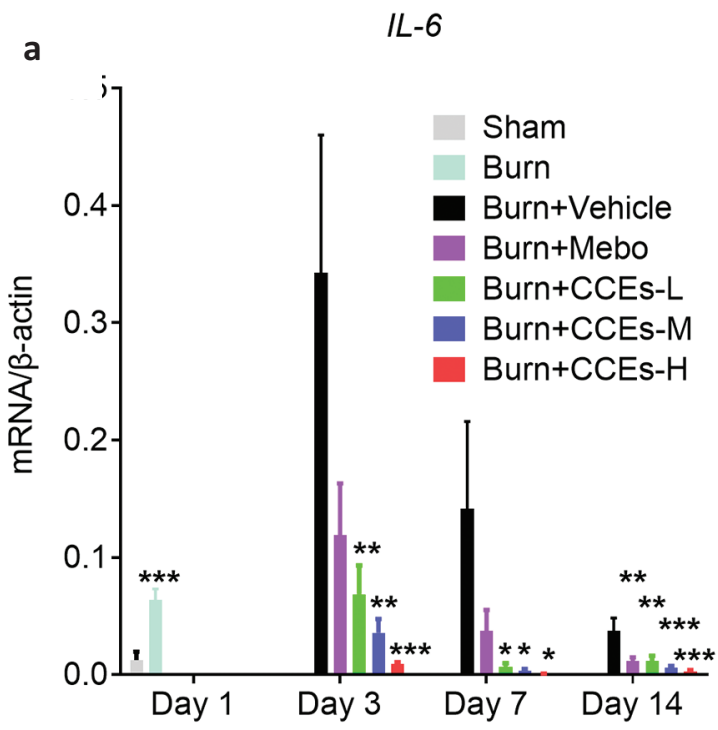

C

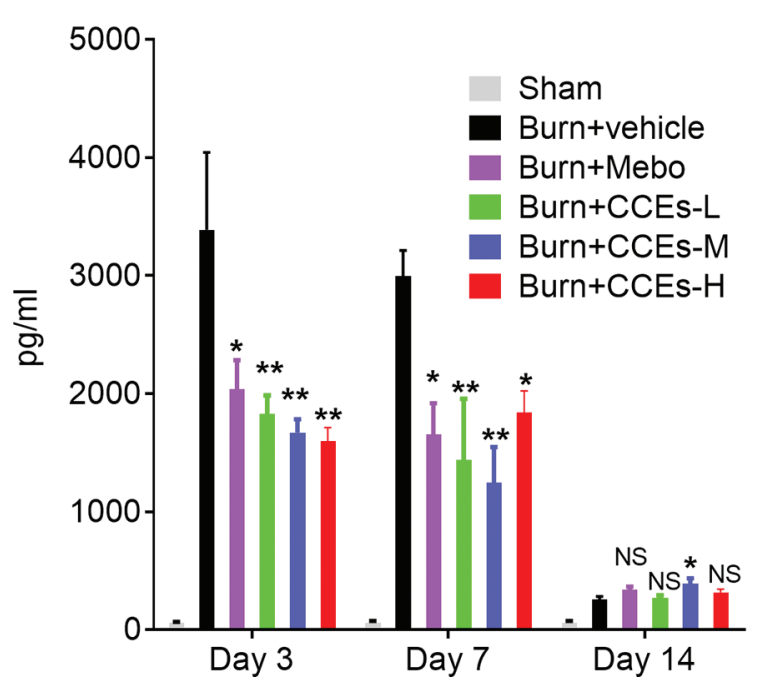

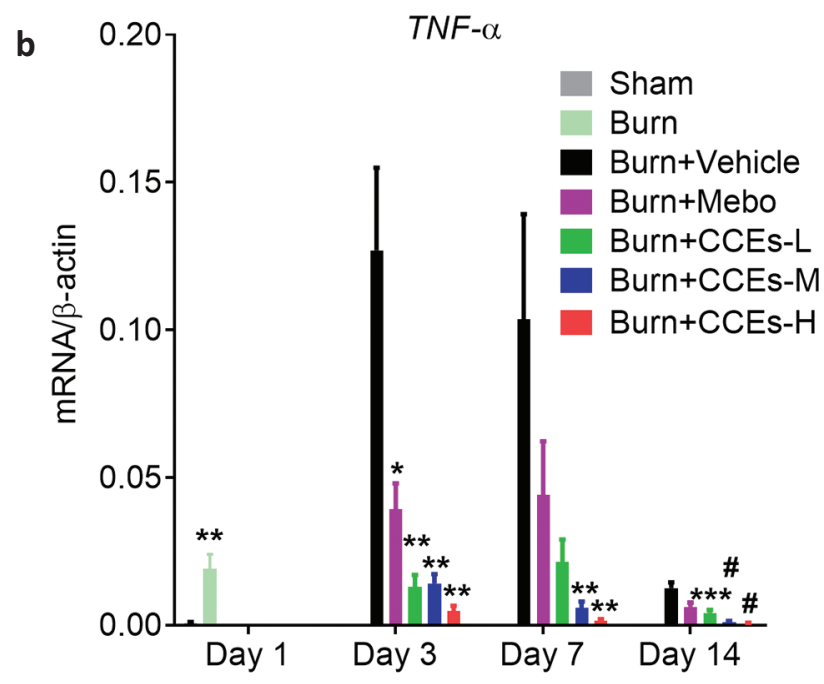

d

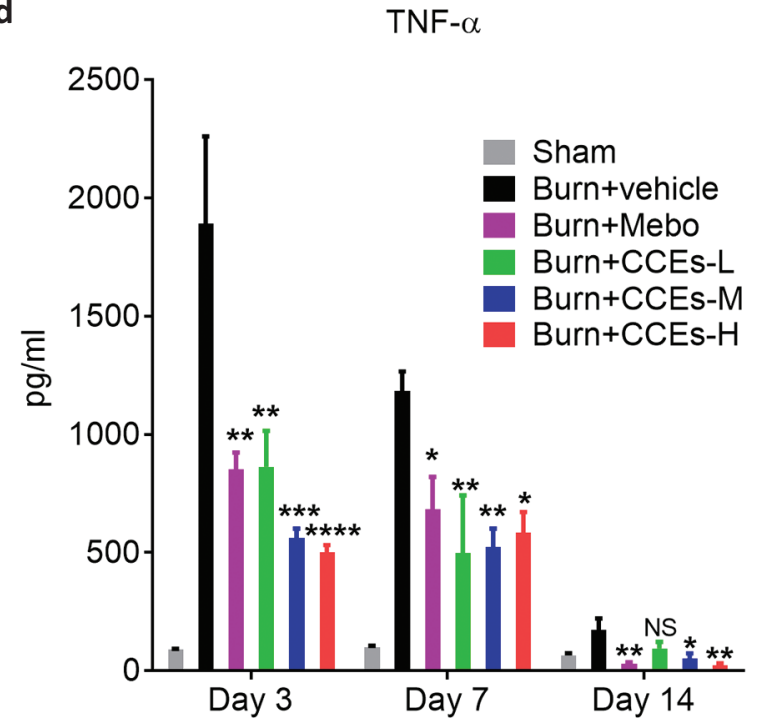

Fig. 4. The effect of Camellia cake extracts (CCEs) on the gene and protein expression of IL- 6 and TNF- $\alpha$. The mice were burned and then administrated with water or Mebo or CCEs $(30,50$, and $100 \mathrm{mg} / \mathrm{mL})$ for 3, 7, and 14 days, and then, skin tissues were collected for gene and protein expression analyses using qRT-PCR and ELISA, respectively. The effect of CCEs on boiling water-induced inflammation demonstrated by the mRNA levels of (a) IL-6, (b) TNF- $\alpha$, and protein levels of IL-6 (c) and TNF- $\alpha(\mathrm{d})$ in the skin scald. The data were presented as the mean \pm SEM. $(* P<0.05, * * P<0.01, * * * P<0.001, \# P<0.0001$ vs. Burn+Vehicle group, NS, not significantly different).

or after LPS stimulation suppressed the cellular levels of phosphorylation of $\mathrm{I}-\mathrm{\kappa} B$ over total I--kB, suggesting that CCEs inhibited inflammation possibly through regulating NF- $\mathrm{kB}$ signaling pathway (Fig. 8c, d).

\section{CCE safety analysis}

To determine the dermal toxic effects of CCEs, $2,000 \mathrm{mg} / \mathrm{kg}$ of CCEs was applied to rat skin. The results showed that there was no abnormality after administration, and the body weight showed an increasing trend during the observation period (Supplementary Table 2). No abnormalities were observed in the gross anatomy, and the $\mathrm{LD}_{50}$ was measured to be greater than $2,000 \mathrm{mg} / \mathrm{kg}$.

Acute oral toxicity $\left(\mathrm{LD}_{50}\right)$ measured by UDP was $2,000 \mathrm{mg} / \mathrm{kg}$. No death was observed in the $550 \mathrm{mg} / \mathrm{kg}$ dose, and the rat mortality in the $2,000 \mathrm{mg} / \mathrm{kg}$ was $44.4 \%$. 
a

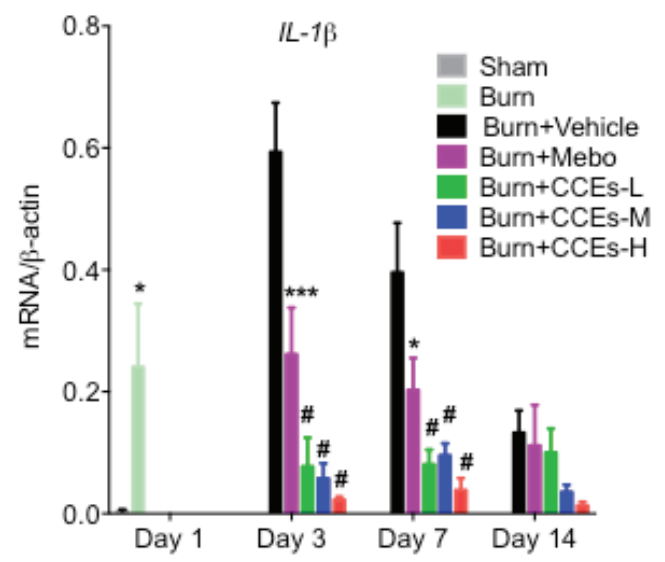

C

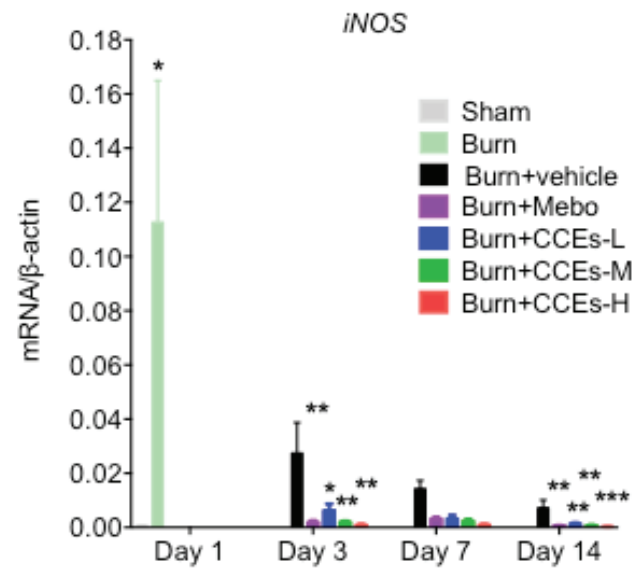

b

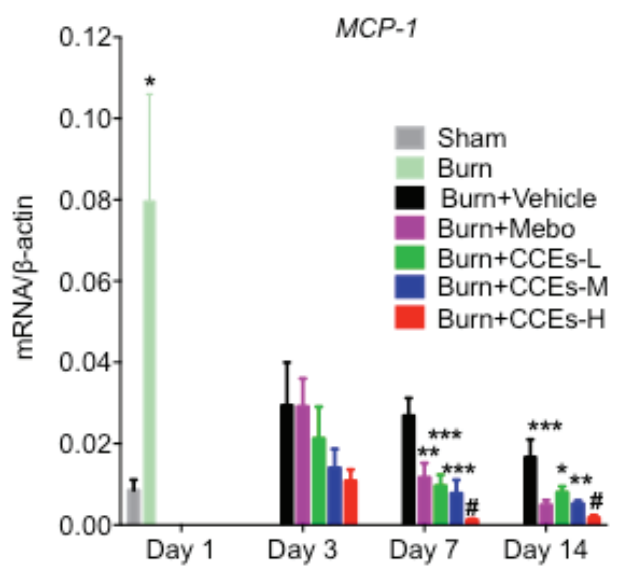

d

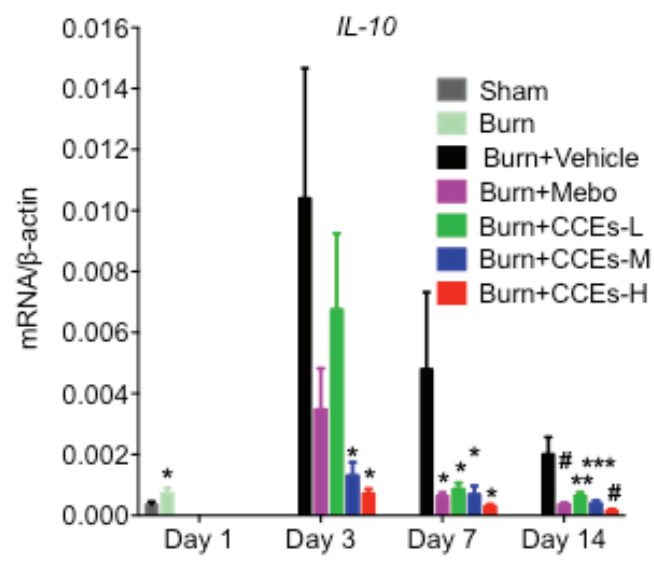

e

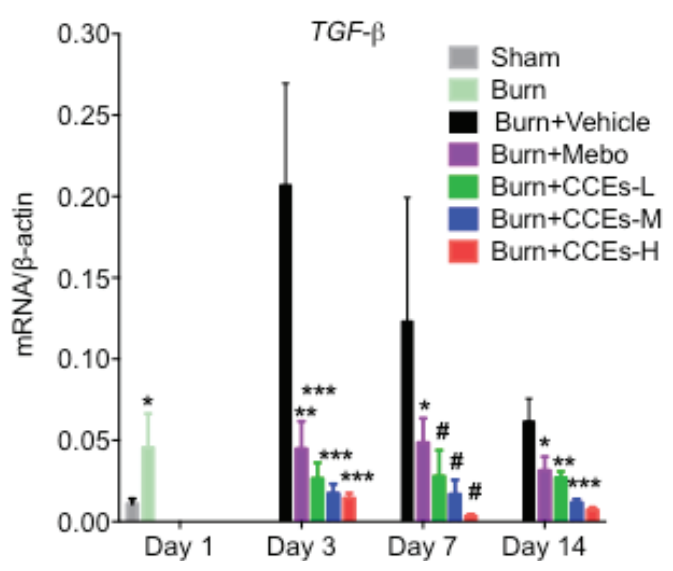

Fig. 5. The effect of Camellia cake extracts (CCEs) on the gene expression of other pro- and anti-inflammatory cytokines. The mice were burned and then administrated with water or Mebo or CCEs (30, 50, and $100 \mathrm{mg} / \mathrm{mL})$ for 3, 7, and 14 days, and then, skin tissues were collected for gene expression analysis using qRT-PCR. The effect of CCEs on the gene expression of (a) IL-1 $\beta$, (b) MCP-1, (c) iNOS, (d) IL-10, and (e) TGF- $\beta$ in the skin scald. The data were presented as the mean \pm SEM. $(* P<0.05$, ${ }^{* *} P<0.01,{ }^{* * *} P<0.001$, \#P<0.0001 vs. Burn+Vehicle group). 
a

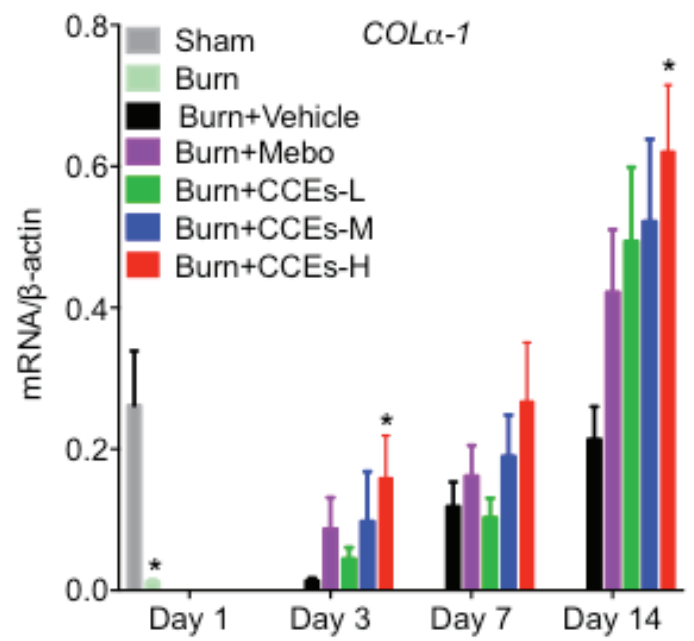

c

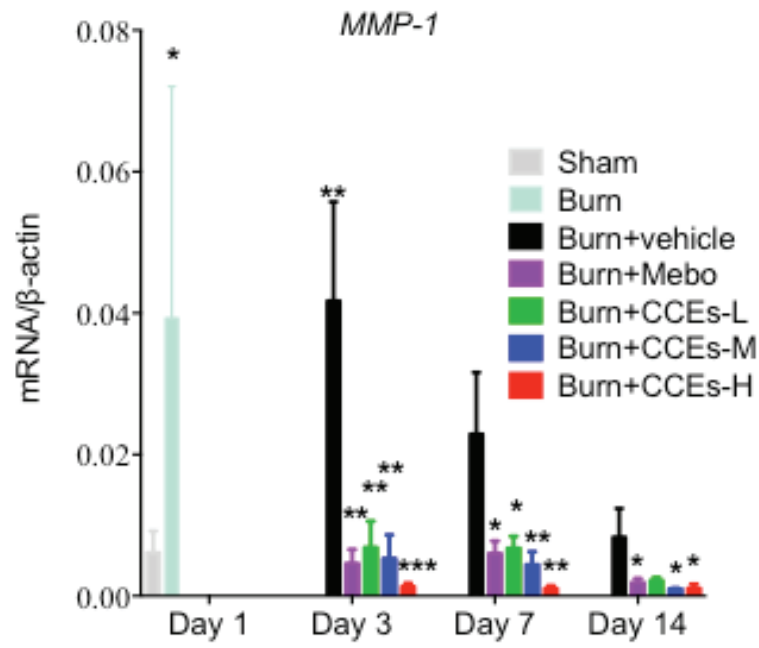

b

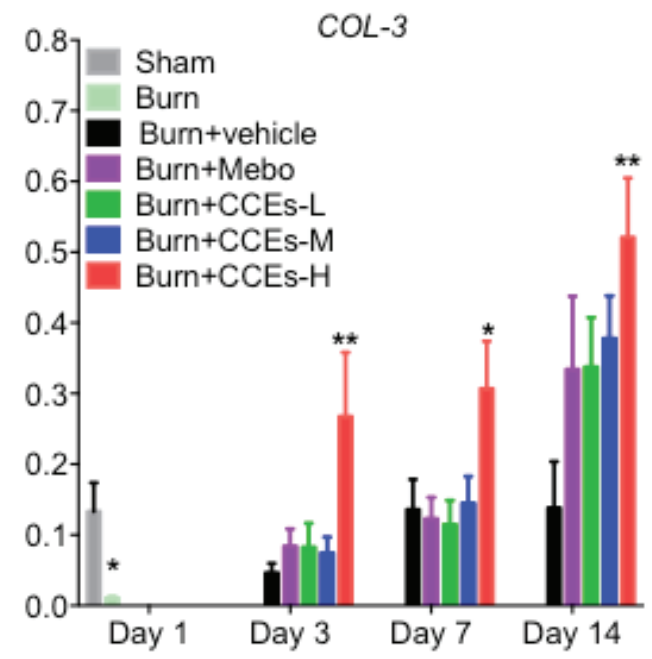

d

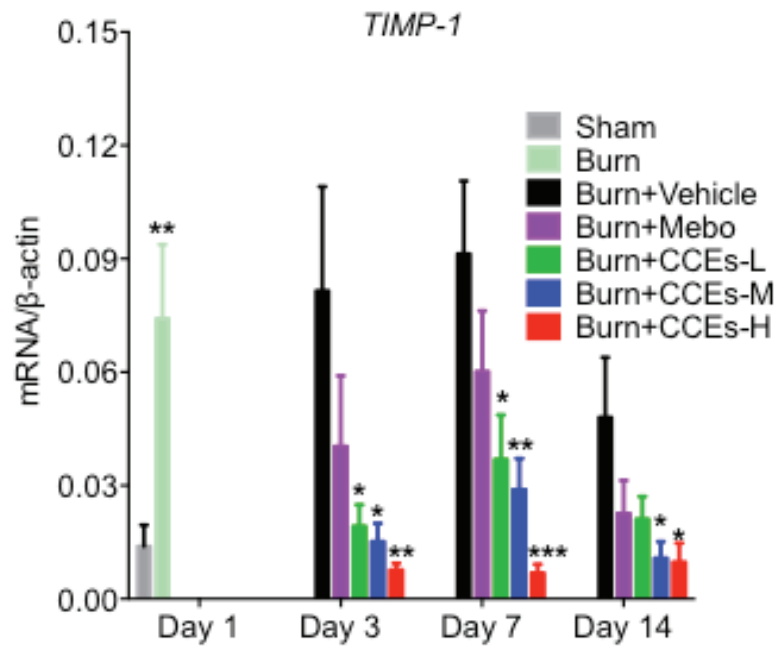

e

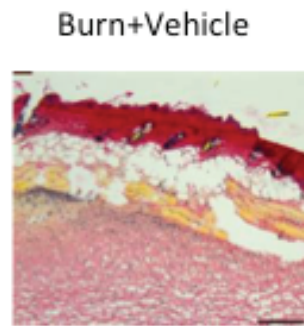

Burn+Mebo

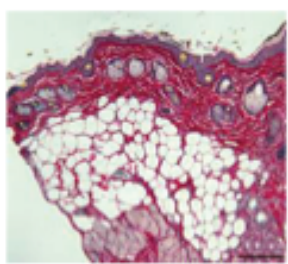

Burn+CCEs-L

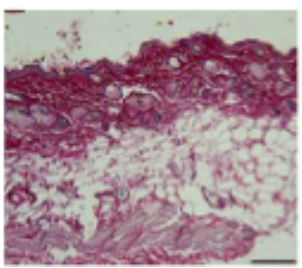

Burn+CCEs-M

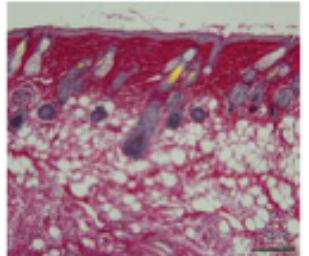

Burn+CCEs-H

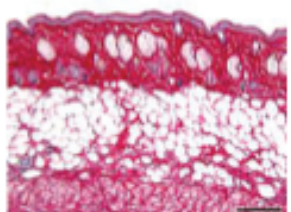

Fig. 6. The effect of Camellia cake extracts (CCEs) on the gene expression of collagen-associated genes. The effect of CCEs on the mRNA expression levels in (a) COL $\alpha-1$, (b) COL-3, (c) MMP-1, and (d) TIMP-1 in the skin scald. The animals were burned and topically administrated with water, Mebo, or CCEs $(30,50$, and $100 \mathrm{mg} / \mathrm{mL}$ ) for 3, 7, and 14 days, and then, skin tissues were collected for gene expression analysis. (e) Collagen staining was performed using Chlorazol fast pink staining kit in skin tissues at day 7 after CCEs treatment. Scar bar: $100 \mathrm{um}$. The data were presented as the mean \pm SEM. $\left({ }^{*} P<0.05,{ }^{* *} P<0.01\right.$, $* * * P<0.001, \# P<0.0001$ vs. Burn+Vehicle group). 
a

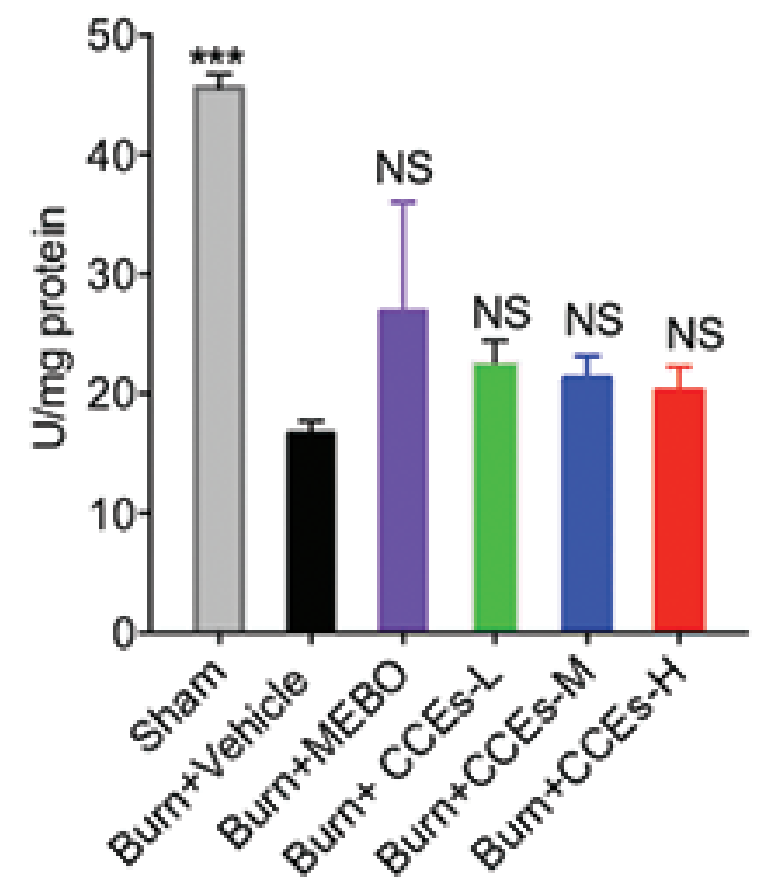

Day 7 CAT

C

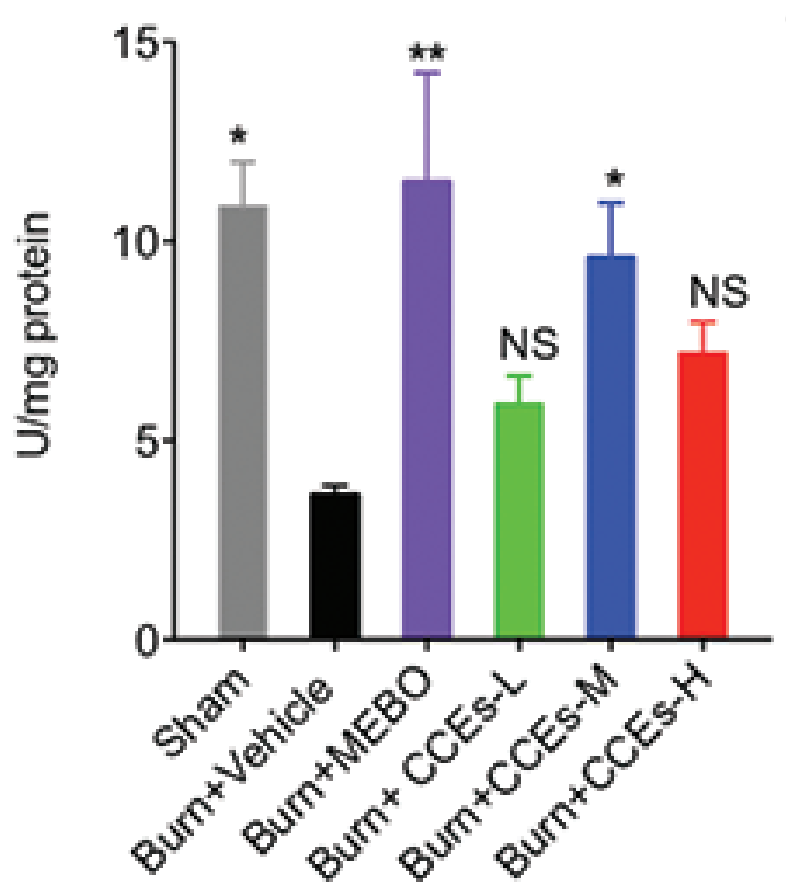

b

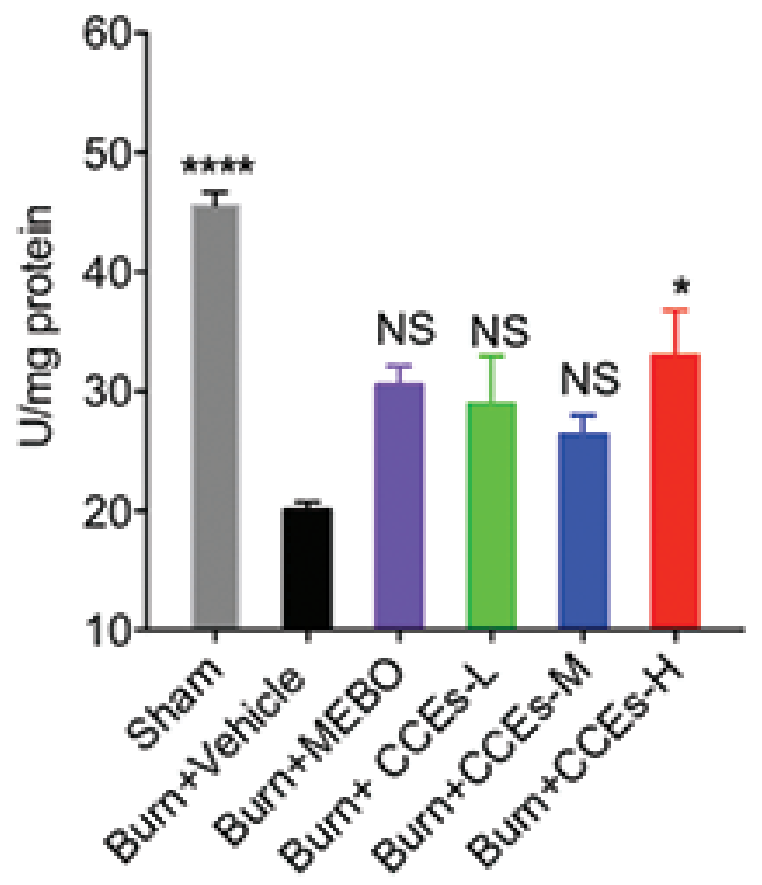

d

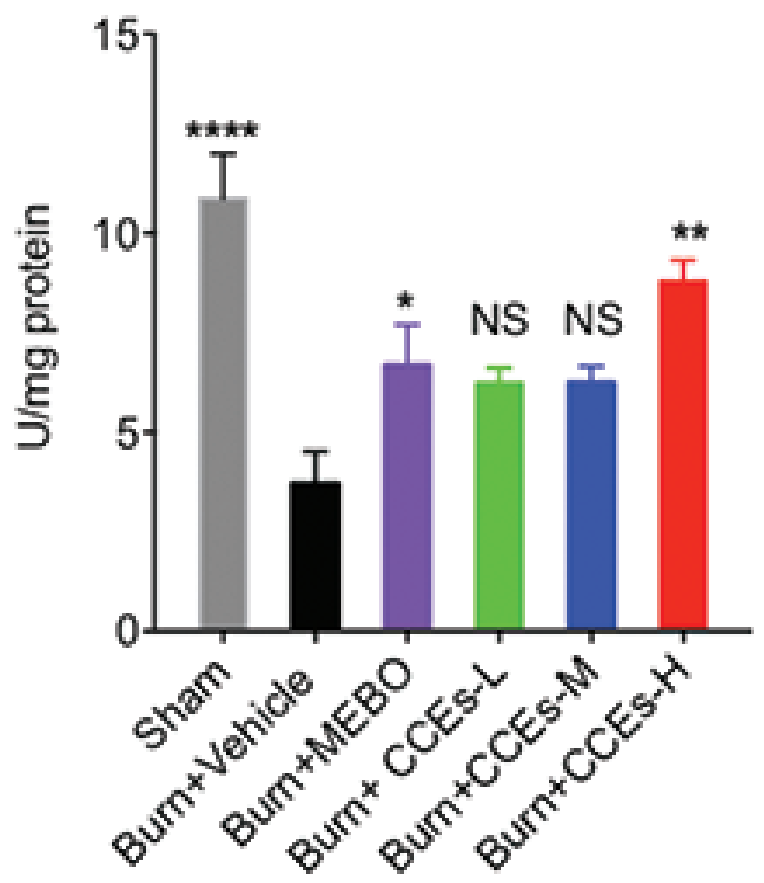

Fig. 7. The effect of Camellia cake extracts (CCEs) on the activity levels of anti-oxidative enzymes. The mice were burned and then administrated with water or Mebo or CCEs $(30,50$, and $100 \mathrm{mg} / \mathrm{mL}$ ) for 7 and 14 days, and then, skin tissues were collected for activity levels of anti-oxidative enzymes. The effect of CCEs on the activity levels of superoxide dismutase (SOD) at day 7 and day 14 (a, b), and catalase (Cat) at day 7 and day 14 (c, d) in the skin scald. The data were presented as the mean \pm SEM. $\left({ }^{*} P<0.05,{ }^{* *} P<0.01,{ }^{* * *} P<0.001, \# P<0.0001\right.$ vs. Burn+Vehicle group, NS, not significantly different). 


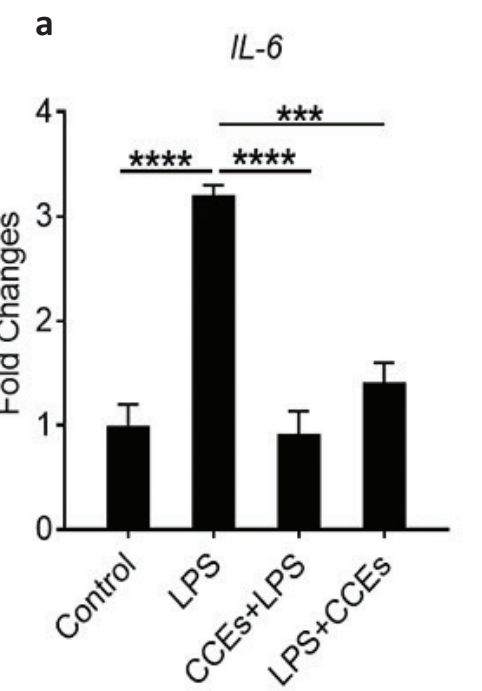

b

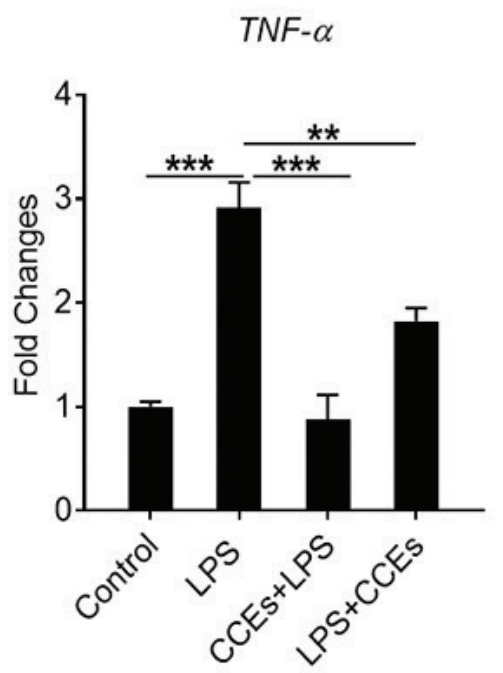

d

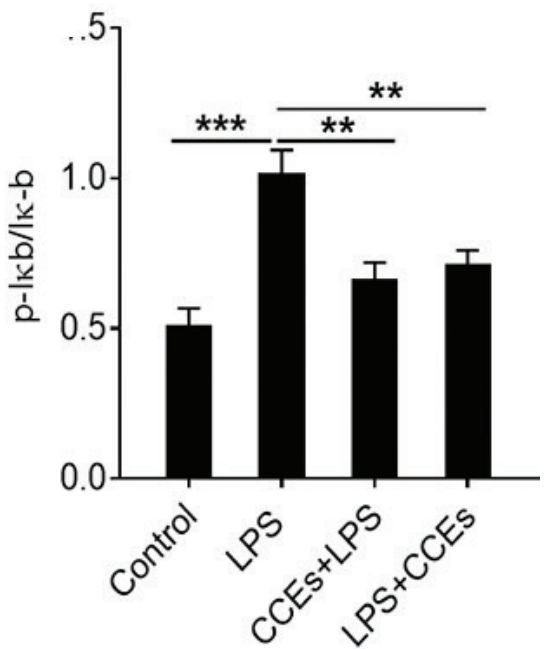

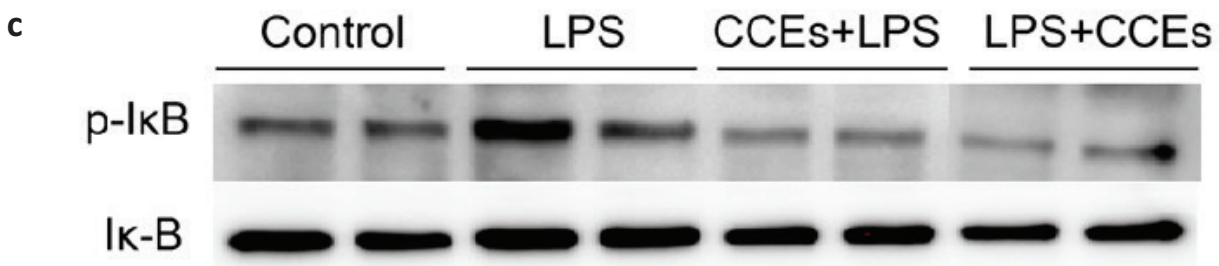

Fig. 8. The anti-inflammatory effect of Camellia cake extracts (CCEs) on the LPS-stimulated skin keratinocyte cells. Skin keratinocytes (Hacat) were treated with CCEs and then stimulated with LPS(CCEs+LPS) or stimulated with LPS and then treated with CCEs (LPS+CCEs). Cells not treated or treated with LPS only were used as Control or LPS groups. After that, cells were collected for gene expression analysis using quantitative PCR and p-I $\kappa$ B/total I $\kappa \mathrm{B}(\mathrm{NF}-\kappa \mathrm{B}$ signaling) analysis using Western-blot. (a) IL-6 gene expression; (b) TNF- $\alpha$ gene expression; (c) Representaive immunoblot images of p-I $\kappa$ B and total I $\kappa$ B; (d) Densitometric quantification of band intensity. The data were a representative of three independent experiments. The data were presented as the mean \pm SEM. $\left({ }^{*} P<0.05,{ }^{*} P<0.01, * * * P<0.001\right.$ vs. LPS group).

No abnormalities were observed in the rats of each dose group (Supplementary Table 3). The body weight of the surviving animals in all dose groups showed an increasing trend during the observation period (Supplementary Table 4).

Ames test was used to test if CCEs can cause host genetic mutation. The results showed that, under the condition with or without a positive drug S9, the numbers of bacterial reverting mutants of $S$. typhimurium strains were observed. There was no significant difference between CCEs and negative control group $(P>0.05)$ (Supplementary Table 5), suggesting that CCEs did not cause a genetic mutation.

\section{Discussion}

CCEs are compounds obtained from Camellia cake. CCEs were shown to have cardioprotective and neuroprotective effects in animal experiments (20-22). Moreover, CCEs were also reported to have potential antimicrobial and anti-cancer effects $(11,23,24)$. In this study, we identified that CCEs from Camellia oil cake have anti-inflammatory effect on boiling water-induced burn damage and can promote skin wound healing. Furthermore, it seems that CCEs have better anti-inflammatory effect than the current commonly used medicine-Mebo, indicating that CCEs may be a good drug candidate for treating burn injury. In addition, the safety analysis of CCE showed that CCEs had no acute toxicity in both transdermal and oral and did not cause genetic mutations;

Wound healing is a complex process with inflammatory response. In the early phase, inflammatory cells such as neutrophils and macrophages were infiltrated. Inflammatory cells produced various inflammatory cytokines such as IL-6, TNF- $\alpha$, IL-1 $\beta$, and MCP-1 $(25,26)$. Our results indicated that CCEs induced a significant dose-dependent reduction in the gene expression of inflammatory cytokines during burn injury. CCEs $(100 \mathrm{mg} / \mathrm{mL})$ strongly decreased the gene expression of inflammatory cytokines 
at various time points. Thereby, CCEs may contribute to wound healing by suppressing the inflammatory response.

Recent study suggested that the TGF- $\beta$ is closely related to inflammation and wound healing. On the one hand, TGF- $\beta$ is one of the major anti-inflammatory cytokines. On the other hand, TGF- $\beta$ directly or indirectly promotes proliferation and differentiation of fibroblasts to synthesize collagen I, III, fibronectin (FN), elastin, and other extracellular matrix components, which stimulate the formation of granulation tissue and promote wound healing $(27,28)$. Interestingly, our results showed that CCEs reduced the gene expression of TGF- $\beta$ in a dose-dependent manner. Similarly, we also observed that another major anti-inflammatory cytokine, IL-10, was also downregulated by CCEs treatment. The upregulation of anti-inflammatory cytokines during inflammation is possibly linked to host negative feedback to control inflammation. However, the detail mechanism needs further investigation.

Type I and Type III collagens (COL $\alpha-1$ and COL-3) play a major role in wound healing (29). COL $\alpha-1$ has a strong tension and determines the hardness of the skin. COL $\alpha-1$ is used as the stent marker, while the elasticity of skin depends on COL-3. Consistently, we observed that CCEs treatment increased the level of COL $\alpha-1$ and Collagen-3 $(C O L-3)$ mRNA, which may promote the skin recovery. MMP-1 is a family member of MMPs, and its expression in normal skin is at a low level. Excessive expression of MMP-1 caused extracellular matrix degradation and delayed wound healing, suggesting that inhibition of MMP-1 gene expression could promote wound healing (30). Tissue Inhibitor of Metalloproteinase-1 (TIMP-1) is an endogenous inhibitor of MMP-1 and plays a key role in the regulation of MMP-1 activity. The ratio of MMP-1 and TIMP-1 would keep the stability of Extracellular matrix (ECM) and its physiological function $(31,32)$. In our study, animals treated with Mebo or CCEs not only decreased levels of MMP-1 mRNA expression but also decreased TIMP-1 expression. Consistently, CCE treatment increased the collagen staining in skin. Therefore, these results demonstrated that CCEs treatment $(30,50,100 \mathrm{mg} / \mathrm{mL})$ might have a potent healing-promoting effect on burn injury. In addition, in vitro experiment confirmed the anti-inflammatory effect of CCEs. However, the detailed molecular mechanism by which CCEs protect skin from the damage induced by boiling water remains unclear. Furthermore, whether camelliaside A and B play critical roles in anti-inflammatory effects of CCEs deserves further investigations.

In summary, we identified that CCEs could protect from boiling water-induced burn inflammation and promote wound healing, possibly by downregulating the gene expression of cytokines and upregulating the gene expression of collagens. In addition, CCEs did not have dermal or oral toxicity and did not cause genetic mutations. CCEs could become an effective, cheap, and safe drug candidate to treat burn damage to human.

\section{Authors' contributions}

Zhiping Liu and Suzhen Wu designed the project, analyzed the data, and wrote the article. Yuxia Liu and Xiaomei Xiao performed experiments and analyzed the data. $\mathrm{Lu} \mathrm{Xie} \mathrm{and} \mathrm{Luling} \mathrm{Ji} \mathrm{performed} \mathrm{the} \mathrm{experiments.}$ All authors read and approved the final version of the manuscript.

\section{Conflict of interest and funding}

The authors declare that they do not have any commercial or associative interest that represents a conflict of interest in connection with the work submitted. This work was supported by funds from the Natural Science Foundation of Jiangxi Province (20171ACB20024 and 20181BAB205032), the National Natural Science Foundation of China (31560260 and 31960163), Camellia Special Project of Gannan Medical University (YC201501), and Collaborative Innovation Center for Gannan Oil-tea Camellia Industrial Development (YK201603 and YK201608) (to Zhiping Liu and Suzhen Wu).

\section{References}

1. Rowan MP, Cancio LC, Elster EA, Burmeister DM, Rose LF, Natesan S, et al. Burn wound healing and treatment: review and advancements. Crit Care 2015; 19: 243. doi: 10.1186/ s13054-015-0961-2

2. Burns W. WHO; 2016. Available from: http://www.who.int/mediacentre/factsheets/fs365/en/ [cited 5 December 2018].

3. Smolle C, Cambiaso-Daniel J, Forbes AA, Wurzer P, Hundeshagen G, Branski LK, et al. Recent trends in burn epidemiology worldwide: a systematic review. Burns 2017; 43(2): 249-57. doi: 10.1016/j.burns.2016.08.013

4. Mahdavian Delavary B, van der Veer WM, van Egmond M, Niessen FB, Beelen RH. Macrophages in skin injury and repair. Immunobiology 2011; 216(7): 753-62. doi: 10.1016/j. imbio.2011.01.001

5. Chodorowska G, Rogus-Skorupska D. Cutaneous wound healing. Ann Univ Mariae Curie Sklodowska Med 2004; 59(2): 403-7.

6. Razavi H, Darvishi MH, Janfaza S. Silver sulfadiazine encapsulated in lipid-based nanocarriers for burn treatment. J Burn Care Res 2018; 39(3): 319-25. doi: 10.1097/BCR.0000000000000602

7. Hirsch T, Ashkar W, Schumacher O, Steinstraesser L, Ingianni G, Cedidi CC. Moist Exposed Burn Ointment (MEBO) in partial thickness burns - a randomized, comparative open mono-center study on the efficacy of dermaheal (MEBO) ointment on thermal 2nd degree burns compared to conventional therapy. Eur $\mathbf{J}$ Med Res 2008; 13(11): 505-10.

8. Cheng YT, Wu SL, Ho CY, Huang SM, Cheng CL, Yen GC. Beneficial effects of Camellia Oil (Camellia oleifera Abel.) on ketoprofen-induced gastrointestinal mucosal damage through upregulation of HO-1 and VEGF. J Agric Food Chem 2014; 62(3): 642-50. doi: 10.1021/jf404614k 
9. Tu PS, Tung YT, Lee WT, Yen GC. Protective effect of Camellia Oil (Camellia oleifera Abel.) against ethanol-induced acute oxidative injury of the gastric mucosa in mice. J Agric Food Chem 2017; 65(24): 4932-41. doi: 10.1021/acs.jafc.7b01135

10. Lee WT, Tung YT, Wu CC, Tu PS, Yen GC. Camellia Oil (Camellia oleifera Abel.) modifies the composition of gut microbiota and alleviates acetic acid-induced colitis in rats. J Agric Food Chem 2018; 66(28): 7384-92. doi: 10.1021/acs. jafc. 8 b02166

11. Xiao X, He L, Chen Y, Wu L, Wang L, Liu Z. Anti-inflammatory and antioxidative effects of Camellia oleifera Abel components. Future Med Chem 2017; 9(17): 2069-79. doi: 10.4155/ fmc-2017-0109

12. Hu JL, Nie SP, Huang DF, Li C, Xie MY, Wan Y. Antimicrobial activity of saponin-rich fraction from Camellia oleifera cake and its effect on cell viability of mouse macrophage RAW 264.7. J Sci Food Agric 2012; 92(12): 2443-9. doi: 10.1002/ jsfa. 5650

13. Ye Y, Xing H, Chen X. Anti-inflammatory and analgesic activities of the hydrolyzed sasanquasaponins from the defatted seeds of Camellia oleifera. Arch Pharm Res 2013; 36(8): 941-51. doi: 10.1007/s12272-013-0138-y

14. Sekine T, Arita J, Yamaguchi A, Saito K, Okonogi S, Morisaki $\mathrm{N}$, et al. Two flavonol glycosides from seeds of Camellia sinensis. Phytochemistry 1991; 30(3): 991-5.

15. Lee HB, Kim EK, Park SJ, Bang SG, Kim TG, Chung DW. Isolation and anti-inflammatory effect of astragalin synthesized by enzymatic hydrolysis of tea seed extract. J Sci Food Agric 2011; 91(13): 2315-21. doi: 10.1002/jsfa.4457

16. Robbins JB, Reinisch L, Ellis DL. Wound healing of 6.45-microm free electron laser skin incisions with heat-conducting templates. J Biomed Opt 2003; 8(4): 594-600. doi: 10.1117/1.1609452

17. Altamirano J, Miquel R, Katoonizadeh A, Abraldes JG, Duarte-Rojo A, Louvet A, et al. A histologic scoring system for prognosis of patients with alcoholic hepatitis. Gastroenterology 2014; 146(5): 1231-9.e1-6. doi: 10.1053/j.gastro.2014.01.018

18. Theunissen D, Seymour B, Forder M, Cox SG, Rode H. Measurements in wound healing with observations on the effects of topical agents on full thickness dermal incised wounds. Burns 2016; 42(3): 556-63. doi: 10.1016/j.burns.2015.09.014

19. Landen NX, Li D, Stahle M. Transition from inflammation to proliferation: a critical step during wound healing. Cell Mol Life Sci 2016; 73(20): 3861-85. doi: 10.1007/s00018-016-2268-0

20. Li YY, Xiao L, Qiu LY, Yan YF, Wang H, Duan GL, et al. Sasanquasaponin-induced cardioprotection involves inhibition of MPTP opening via attenuating intracellular chloride accumulation. Fitoterapia 2017; 116: 1-9. doi: 10.1016/j. fitote. 2016.11.003

21. Qiu LY, Duan GL, Yan YF, Li YY, Wang H, Xiao L, et al. Sasanquasaponin induces increase of $\mathrm{Cl} / \mathrm{HCO} 3$ exchange of anion exchanger 3 and promotes intracellular $\mathrm{Cl}$ efflux in hypoxia/reoxygenation cardiomyocytes. Mol Med Rep 2017; 16(3): 2953-61. doi: 10.3892/mmr.2017.6882
22. Ye Y, Xing H, Li Y. Nanoencapsulation of the sasanquasaponin from Camellia oleifera, its photo responsiveness and neuroprotective effects. Int J Nanomed 2014; 9: 4475-84. doi: 10.2147/ IJN.S64313

23. Zeng J, Chen S, Li N, Chen L, Su J, Niu G, et al. Sasanquasaponin from Camellia oleifera Abel. induces apoptosis via Bcl-2, Bax and caspase- 3 activation in HepG2 cells. Mol Med Rep 2015; 12(2): 1997-2002. doi: 10.3892/mmr.2015.3666

24. Chen L, Chen J, Xu H. Sasanquasaponin from Camellia oleifera Abel. induces cell cycle arrest and apoptosis in human breast cancer MCF-7 cells. Fitoterapia 2013; 84: 123-9. doi: 10.1016/j. fitote. 2012.11.009

25. Koh TJ, DiPietro LA. Inflammation and wound healing: the role of the macrophage. Expert Rev Mol Med 2011; 13: e23. doi: 10.1017/S1462399411001943

26. Pastar I, Stojadinovic O, Yin NC, Ramirez H, Nusbaum AG, Sawaya A, et al. Epithelialization in wound healing: a comprehensive review. Adv Wound Care (New Rochelle) 2014; 3(7): 445-64. doi: 10.1089/wound.2013.0473

27. Pakyari M, Farrokhi A, Maharlooei MK, Ghahary A. Critical role of transforming growth factor beta in different phases of wound healing. Adv Wound Care (New Rochelle) 2013; 2(5): 215-24. doi: 10.1089/wound.2012.0406

28. Weber CE, Li NY, Wai PY, Kuo PC. Epithelial-mesenchymal transition, TGF-beta, and osteopontin in wound healing and tissue remodeling after injury. J Burn Care Res 2012; 33(3): 311-18. doi: 10.1097/BCR.0b013e318240541e

29. Ganeshkumar M, Ponrasu T, Krithika R, Iyappan K, Gayathri VS, Suguna L. Topical application of Acalypha indica accelerates rat cutaneous wound healing by up-regulating the expression of Type I and III collagen. J Ethnopharmacol 2012; 142(1): 14-22. doi: 10.1016/j.jep.2012.04.005

30. Aust MC, Knobloch K, Reimers K, Redeker J, Ipaktchi R, Altintas MA, et al. Percutaneous collagen induction therapy: an alternative treatment for burn scars. Burns 2010; 36(6): 836-43. doi: 10.1016/j.burns.2009.11.014

31. Babaei S, Bayat M. Pentoxifylline accelerates wound healing process by modulating gene expression of MMP-1, MMP-3, and TIMP-1 in normoglycemic rats. J Invest Surg 2015; 28(4): 196-201. doi: 10.3109/08941939.2014.1002642

32. Cai QW, Li J, Li XQ, Wang JQ, Huang Y. Expression of STAT3, MMP-1 and TIMP-1 in gastric cancer and correlation with pathological features. Mol Med Rep 2012; 5(6): 1438-42. doi: 10.3892/mmr.2012.849

\section{*Suzhen Wu and Zhiping Liu}

School of Basic Medicine

Gannan Medical University

Ganzhou

Jiangxi 341000

China

Email:Wusuzhen2005@|26.com; Zhiping.Liu@gmu.cn 